\title{
SMART WAY OF COMMUNICATION FOR DISASTER RECOVERY
}

\author{
Dr. Newlin Rajkumar. $M^{1}$, Ms. Malarvizhi. $S^{2}$ \\ Dr. Venkatesa Kumar. $V^{3}$ \\ ${ }^{1}$ Assistant Professor, ${ }^{2}$ P.G.Scholar,${ }^{3}$ Assistant Professor. \\ Anna University Regional Campus, Coimbatore-641046. \\ $\underline{\text { newlin_rajkumar@yahoo.co.in }}{ }^{1}, \underline{\text { malar.cbe61@gmail.com }}{ }^{2}, \underline{\text { mail2venkatesa@gmail.com }}^{3}$
}

\begin{abstract}
Telecommunication infrastructures are often seriously disabled when major natural disasters occur. Services like Internet connectivity are often lost in such events. This is quite unfortunate as many mobile communication devices are still functioning, and can be used for example to help rescuers to localize and access victims trap in particular are as of the disaster zone. A study on communication during the disaster recovery is made and proposed a Emergency-Relay, which is designed and implemented on a smart phones to provide a communication for disaster recovery. Emergency-Relay includes Help-Button. That provides data communications for rescue workers by send-out emergency messages as energy-efficiently discovers nearby messaging nodes and Emergency-Relay is implemented as a prototype application on the Android platform using the Wi-Fi interface.
\end{abstract}

Keywords: Disaster Recovery, Emergency-relay, Telecommunication, command Center.

\section{I.INTRODUCTION}

In situations such as the foregoing where infrastructure connections are destroyed or unreliable, peerto-peer (P2P) and delay-tolerant networking (DTN) technologies can help provide communication for relief operations. P2P connections (via Wi-Fi or Blue tooth) would allow people to directly connect and communicate with each other, eliminating the need for infrastructure to send data or messages. This would require $\mathrm{P} 2 \mathrm{P}$-capable devices such as mobile phones to be within range, however, a condition that may not always be satisfied in emergency conditions. Therefore DTN (store-and forward) functionality may play a complementary role institution like these.

Operating in tandem, a combination of these technologies would allow, for example, the transmission of information needed for damage assessment, basic communications, to coordinate and launch relief efforts, to pursue recovery and reconstruction, coordinate and provide police presence, undertake medical missions, and conduct public health surveillance. Message and data passing even in the absence of conventional communications infrastructure would still be possible as peer devices could receive, hold and relay information until the intended recipient is found. This is useful especially where there are teams of rescue and relief personnel, or even members of the affected communities, constantly on the move.

There are applications that have the ability to support infrastructure less communications. One example is Fire Chat [1] which sends messages via the Internet if connected and thru $\mathrm{Wi}-\mathrm{Fi}$ and Blue tooth if there is no Internet access. Although this has been made popular by its use in several political movements like the Occupy HK movement, it has also been adopted and positioned for potential use in disaster response by government agencies like the Marikina city government in the Philippines. One issue however is that applications like these are proprietary and closed in nature, making it difficult to further develop and add new functionalities, or to build other useful applications from their components.

On the other hand the few available open frameworks and tools still do not integrate the functionalities needed for effective infrastructure less communication. P2P and DTN technologies, for instance, are not standard features in these frameworks, much less in most mobile applications. Existing mobile applications must be modified to meet the required development environment and should include custom libraries to integrate these technologies.

This makes it difficult to easily adapt, improve or build mobile applications for infrastructure less communications in general, and for disaster risk and management in particular.

\section{II.PROPOSED WORK}

Communications in disaster recovery without using cellular network and low power consumption is proposed in this approach. We have designed and implemented a system called Emergency-Relay, which provides smart phones the capabilities of communications in disaster recovery. Specifically, consists of one Help-Button system. The Helpbutton system used to communicate command Centre through node by node. If trapped survivors press the HelpButton in disaster period the message send-out to command Centre with their location by using IP configuration and GPRS. It enables communications among rescue workers. That system energy-efficiently sends out emergency messages so as to assist rescue operations.

We have implemented Emergency-Relay as a prototype application on the Android platform and deployed it on off-the shelf smart phones. 


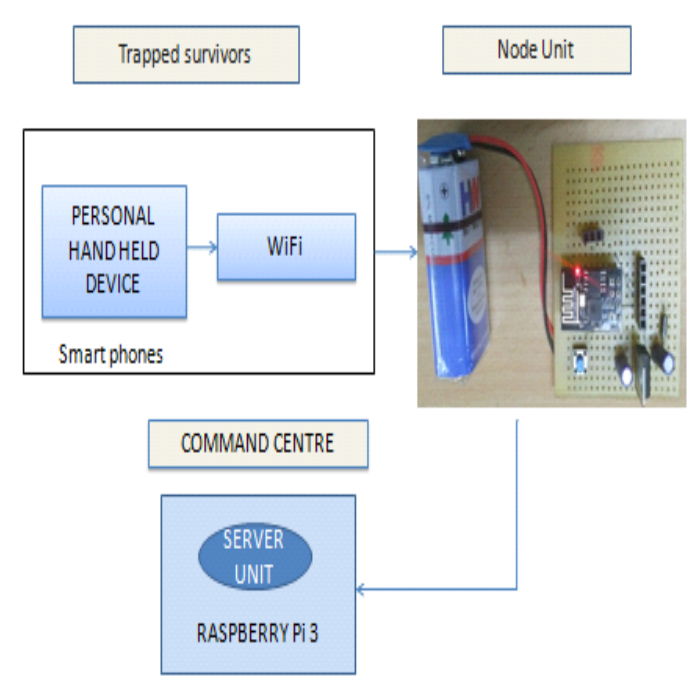

Figure 3 Architecture of Smart way of communication for disaster recovery

Experiment results show that Emergency-Relay can properly fulfill communication requirements and greatly facilitate rescue operations in disaster recovery.

\section{RESULTS}

\section{Architecture:}

An architecture of Smart way of communication for disaster recovery is shown in the above figure. The personal hand held device (smartphones) has ability to transfer the data and also has Wi-Fi fesility. The smartphones has Emergency-Relay application in default, which provides Help-Button system, if the trapped survivors press the HelpButton in disaster period the emergency message send-out to command centre with their location through node by node and GPRS is used identified their positioning. Wi-Fi is a communicating medium. Raspberry pi is used to act as a command centre(server). It was remotely connected to node unit. Emergency messages viewed in command centre by the help of raspberry pi. And then the rescue workers get information from the server, so as to assit for rescue operation.

The following components are needed to used for providing communication for disaster recovery,

- Personal hand held device (Smartphones)

- Node unit

- GPRS

- Arduino Uno

- USB to serial convertor

- Raspberry pi

\section{Personal Hand Held Device :}

A mobile device is a small computing device, typically small enough to be handheld, having a display screen with a miniature keyboard and, in some models, a touchscreen which enables the user to use a "virtual keyboard" that is displayed on screen, along with other icons and "buttons" that can be pressed. Mobile devices typically weighing less than 2 pounds $(0.91 \mathrm{~kg})$. A handheld computing device has an operating system (OS), and can run mobile application.

\section{GPRS :}

General Packet Radio Service (GPRS) is a packet oriented mobile data service on the $2 \mathrm{G}$ and $3 \mathrm{G}$ cellular communication system's global system for mobile communications (GSM).

\section{Node unit:}

The node unit contains WiFi module, Switch,reset button, capacitor(63V), 2voltage regulator, ISB insystem programming,USB serial convertor, diode,Battery. It can be programmed the capability of sending message to another node by Arduino controller using Arduino 1.6 version software.

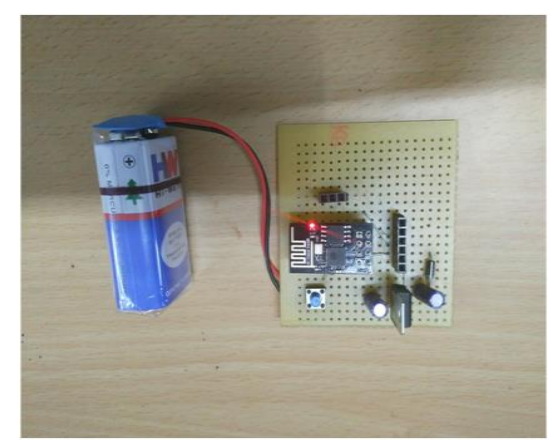

Figure 2.Node Unit

\section{Raspberry pi (Model B) :}

The Raspberry pi is used in our model. Raspberry $\mathrm{Pi}$ is a single board computer with Linux or other small operating systems. It was developed by Raspberry Pi foundation in UK for the use of computer science education. The second version of the Raspberry $\mathrm{Pi}$ is used in this project.

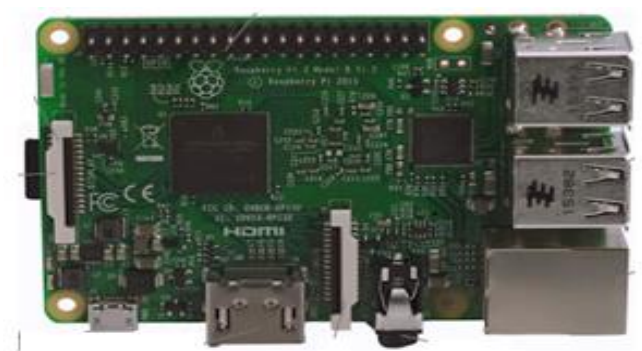

Fig 3.Raspberry pi

It consists of an ARM 1176JZF-S processor, which runs at $700 \mathrm{MHz}$ clock speed, 512MB SDRAM shared with GPU, a Video Core IV GPU, 2 USB port, $1100 \mathrm{M} \mathrm{bit/s}$ Ethernet port, one video and audio output, one HDMI output. It also has 26 pins including 8 General purpose Input/output (GPIO), one SPI bus, one I2C bus, 21

one UART bus and 3.3V, GND and 5V.The Raspberry Pi needs an external Secure Digital(SD) card to store its operating system and also all the user data. Hence the Raspberry pi can be used as a really powerful microcontroller which can accomplish almost any functions, and also it can act as a normal use computer with keyboard, 
mouse and monitor connected.

\section{USB to Serial Convertor :}

The USB to Serial convertor is used to dump the program into node unit by using Arduino controller.

\section{Arduino Uno :}

Arduino/Genuino Uno is a microcontroller board based on the ATmega328P (Data sheet). It has 14 digital input/output pins (of which 6 can be used as PWM outputs), 6 analog inputs, a $16 \mathrm{MHz}$ quartz crystal, a USB connection, a power jack, an ICSP header and a reset button. It contains everything needed to support the microcontroller; simply connect it to a computer with a USB cable or power it with a AC-to-DC adapter or battery to get started.

\section{RESULT :}

If the switch node is ON Continuosly message received from the trapped survivors.If the switch node is OFF message was not received from the trapped survivors.

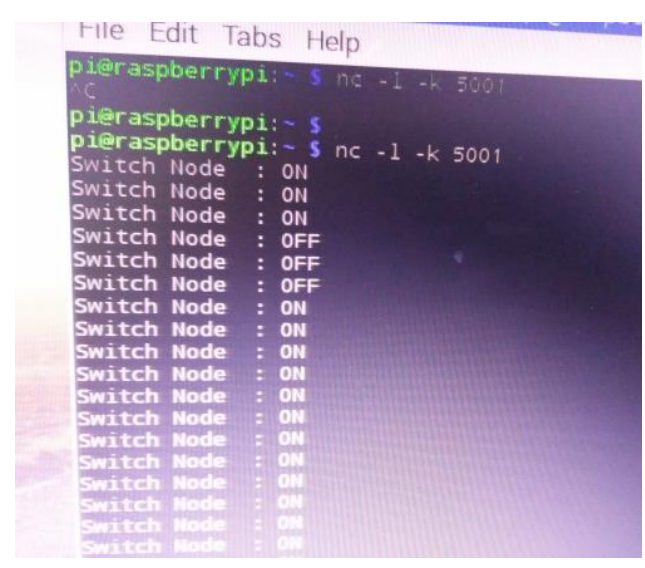

ON - Message Received Continuosly OFF - Message Not Received

TABLE 1.EXISTING APPROACH FOR COMMUNICATION DURING DISASTER RECOVERY

\begin{tabular}{|c|c|c|c|c|c|}
\hline S.no & Paper Title & Methodology & Benefits & Limitations & Ref \\
\hline 1 & $\begin{array}{l}\text { E-DARWIN: Energy } \\
\text { Aware Disaster } \\
\text { Recovery Network using } \\
\text { Wi-Fi Tethering }\end{array}$ & $\begin{array}{l}\text { Energy Aware } \\
\text { Disaster Recovery } \\
\text { Network using Wi- } \\
\text { Fi Tethering (E- } \\
\text { DARWIN) }\end{array}$ & $\begin{array}{l}\text { Provides the data } \\
\text { capturing task among } \\
\text { wireless devices based } \\
\text { on their capabilities, } \\
\text { available energy } \\
\text { effectively. }\end{array}$ & $\begin{array}{l}\text { Delay in data } \\
\text { collection }\end{array}$ & 7 \\
\hline 2 & $\begin{array}{l}\text { Efficient communication } \\
\text { over cellular networks } \\
\text { with network coding in } \\
\text { emergency scenarios }\end{array}$ & $\begin{array}{l}\text { propose a network } \\
\text { architecture that } \\
\text { uses cellular } \\
\text { networks and WiFi } \\
\text { connections }\end{array}$ & $\begin{array}{l}\text { random linear NC } \\
\text { scheme derives the } \\
\text { successful decoding } \\
\text { probability }\end{array}$ & $\begin{array}{l}\text { Low performance } \\
\text { Network coding } \\
\text { in terms of the } \\
\text { delivery ratio }\end{array}$ & 8 \\
\hline 3 & $\begin{array}{l}\text { Cyber Physical System } \\
\text { Using Intelligent } \\
\text { Wireless Sensor } \\
\text { Actuator Networks for } \\
\text { Disaster Recovery }\end{array}$ & $\begin{array}{l}\text { decision tree } \\
\text { technique, } \\
\text { intelligent Wireless } \\
\text { Sensor Network } \\
\text { with Cyber physical } \\
\text { System (CPS) }\end{array}$ & $\begin{array}{l}\text { real world physical } \\
\text { status and conditions } \\
\text { and to actuate disaster } \\
\text { recovery system }\end{array}$ & $\begin{array}{l}\text { performance } \\
\text { accuracy is poor } \\
\text { due to wide } \\
\text { distance }\end{array}$ & 9 \\
\hline 4 & $\begin{array}{l}\text { Cluster-based and } \\
\text { cellular approach to fault } \\
\text { detection and recovery in } \\
\text { wireless sensor networks }\end{array}$ & $\begin{array}{l}\text { cluster-based failure } \\
\text { detection and } \\
\text { recovery scheme }\end{array}$ & $\begin{array}{l}\text { Cluster-based and } \\
\text { cellular approach to } \\
\text { fault detection and } \\
\text { recovery in wireless } \\
\text { sensor networks }\end{array}$ & $\begin{array}{l}\text { Issues occurred } \\
\text { regarding } \\
\text { connectivity and } \\
\text { data loss }\end{array}$ & 10 \\
\hline 5 & $\begin{array}{l}\text { A Collective Intelligence } \\
\text { Resource Management } \\
\text { Dynamic Approach for } \\
\text { Disaster Management: A } \\
\text { Density Survey of } \\
\text { Disasters Occurrence }\end{array}$ & $\begin{array}{l}\text { Collective } \\
\text { Intelligence } \\
\text { Resource } \\
\text { Management } \\
\text { Dynamic Approach }\end{array}$ & $\begin{array}{l}\text { Provides effective } \\
\text { Disaster Management } \\
\text { using dynamic } \\
\text { approach }\end{array}$ & $\begin{array}{l}\text { Decision making } \\
\text { is difficult due to } \\
\text { data complexity } \\
\text { and volume }\end{array}$ & 11 \\
\hline 6 & $\begin{array}{l}\text { Lifetime enhancement of } \\
\text { disaster recovery } \\
\text { systems based on IEEE } \\
802.11 \text { s wireless mesh } \\
\text { networks }\end{array}$ & $\begin{array}{l}\text { wireless mesh } \\
\text { network and lifetime } \\
\text { enhancement } \\
\text { algorithm }\end{array}$ & $\begin{array}{l}\text { allows to shut down } \\
\text { non necessary nodes } \\
\text { and to keep them for a } \\
\text { later usage while still } \\
\text { keeping network } \\
\text { connectivity }\end{array}$ & $\begin{array}{l}\text { This will work till } \\
\text { the battery } \\
\text { powered devices } \\
\text { still available in } \\
\text { the disaster region }\end{array}$ & 12 \\
\hline
\end{tabular}




\section{CONCLUSION}

In this work, we propose Emergency-Relay, which is designed and implemented on a smart phones to provide a communication for disaster recovery. Emergency-Relay includes Help-Button. That provides data communications for rescue workers by send-out emergency messages as energy-efficiently discovers nearby messaging nodes and Emergency-Relay is implemented as a prototype application on the Android platform using the WiFi interface and The evaluation results demonstrate that Emergency-Relay can accomplish various message transmissions with affordable power consumption and delay, and greatly reduce the energy consumption of sending out emergency messages. In the phase I, we implemented our work in top down approach.ted In the future work of this paper placing the number of nodes should be reduced and extended the coverage area of node unit.

\section{REFERENCES}

[1] FireChat.[Online].Available:http://opengarden.com/howto/

[2] Ellerton, John, Andrew Lord, Paul Gunning, Kristan Farrow, Paul Wright, Daniel King, and David Hutchison. "Prospects for software defined networking and network function virtualization in media and broadcast." In Annual Technical Conference and Exhibition, SMPTE 2015, pp. 1-21. SMPTE, 2015.

[3] Santos, Jan Vincent, Danah Veronica Torres, Monica KathrinaVillanoy, Cedric Angelo Festin, John Norman Doctor, and RoelOcampo. "Rapid mobile development with ARC: Application framework for robust communications for disaster risk reduction and management." In Wireless and Mobile Computing, Networking and Communications (WiMob), 2016 IEEE 12th International Conference on, pp. 1-6. IEEE, 2016.

[4] Lu, Zongqing, Guohong Cao, and Thomas La Porta. "Networking smart phones for disaster recovery." In Pervasive Computing and Communications (PerCom), 2016 IEEE International Conference on, pp. 1-9. IEEE, 2016

[5] E. Rosas, F. Garay, N. Hidalgo, and O. Marin, "Mobilityaware DTN protocols for post-disaster scenarios," in 2015 2nd International Conference on Information and Communication Technologies for Disaster Management (ICT-DM), Nov 2015, pp. 193-199.

[6] D. Krishnaswamy, R. Krishnan, A. Qamar and K. Rajagopal,"SankatEdge: A distributed network edge infrastructure framework for disaster recovery", 2014 IEEE Global Humanitarian Technology Conference South Asia Satellite (GHTC-SAS), 2014.

[7] Raj, Mayank, Krishna Kant, and Sajal K. Das. "EDARWIN: energy aware disaster recovery network using wifi tethering." In Computer Communication and Networks (ICCCN), 2014 23rd International Conference on, pp. 1-8. IEEE, 2014

[8] .Do-Duy, Tan, and M. A. Vázquez-Castro. "Efficient communication over cellular networks with network coding in emergency scenarios." In Information and Communication Technologies for Disaster Management (ICT-DM), 2015 2nd International Conference on, pp. 7178. IEEE, 2015.
[9] Mariappan, Ramasamy, PV Narayana Reddy, and Chang Wu. "Cyber Physical System Using Intelligent Wireless Sensor Actuator Networks for Disaster Recovery." In Computational Intelligence and Communication Networks (CICN), 2015 International Conference on, pp. 95-99. IEEE, 2015.

[10] Akbari, Abolfazl, and NedaBeikmahdavi. "Cluster-based and cellular approach to fault detection and recovery in wireless sensor networks." In Advanced Computer Theory and Engineering (ICACTE), 2010 3rd International Conference on, vol. 5, pp. V5-148. IEEE, 2010.

[11] Asimakopoulou, Eleana, NikBessis, SteliosSotiriadis, FatosXhafa, and Leonard Barolli. "A collective intelligence resource management dynamic approach for disaster management: A density survey of disasters occurrence." In Intelligent Networking and Collaborative Systems (INCoS), 2011 Third International Conference on, pp. 735-740. IEEE, 2011.

[12] Hepner, Christopher, and Roland Muenzner. "Lifetime enhancement of disaster recovery systems based on IEEE 802.11 s wireless mesh networks." In Wireless and Mobile Computing, Networking and Communications (WiMob), 2015 IEEE 11th International Conference on, pp. 91-99. IEEE, 2015.

[13] Barz, Hans W., and Gregory A. Bassett. Multimedia Networks: Protocols, Design and Applications. John Wiley \& Sons, 2016.

\section{BIOGRAPHY}

First Author Dr. M. Newlin Rajkumar is presently working as Assistant Professor in The Department of Computer Science and Engineering, Anna University Regional Campus, Coimbatore. He received his Bachelor of Engineering Degree from Bharathiyar University, Master of Science (M.S by Research) from National Chiao Tuns University, Taiwan and Master of Business Administration (IBM) from Anna University, Coimbatore. Presently he is pursuing his Ph.D in Anna University Chennai. He has more than ten years of Teaching Experience. He has published several papers in reputed International Journals. $\mathrm{He}$ is a Professional Member of ACM, Member of IEEE India Council, Life Member of International Association of Computer Science and Information Technology, International Association of Engineers and in many International Associations. His research interest includes cloud Computing, Internet of Things, Big Data Analytics, Network Security, Security Protocols and Network Management.

Second Author S.Malarvizhi is pursing M.E Computer Science and Engineering (Specialization with Networks) in the Department of Computer Science and Engineering, Anna University Regional Campus, Coimbatore. She received her Bachelor of Engineering Degree from SNS College Of Engineering. Her research interests are Wireless sensor networking, Network Security, IoT (Internet of things).

Third Author Dr.V. Venkatesakumar is presently working as Assistant Professor in The Department of Computer Science and Engineering, Anna University Regional Campus, Coimbatore. He received his Bachelor of Engineering Degree from Bharathiyar University, Master of Engineering Degree and Ph.D from Anna University Chennai. He has more than ten years of Teaching Experience. He has published many papers in reputed International Journals and has Chaired many Conferences. He is a Life Member of International Association of Computer Science and Information Technology, International Association of Engineers and in many International Associations. His research interest includes Cloud Computing, Internet of Things, Big Data Analytics, Operating System, Software Engineering and Web Technologies. 